\title{
1 Impact of Spatial, Spectral, and Radiometric Properties of Multispectral Imagers on Glacier \\ 2 Surface Classification
}

$4 \quad$ Allen POPE ${ }^{\mathrm{a}, * 1}$, W. Gareth REES ${ }^{\mathrm{a}}$

$5 \quad{ }^{a}$ Scott Polar Research Institute, University of Cambridge, Lensfield Road, Cambridge CB2 1ER, United

$6 \quad$ Kingdom

8 *Corresponding author, allen.pope@ post.harvard.edu, +1 (303) 492-9077

10 Keywords: glaciers, snow, multispectral, classification, principal component analysis.

12 Abstract

13 Using multispectral remote sensing, glacier surfaces can be classified into a range of zones. The

14 properties of these classes are used for a range of glaciological applications including mass balance

15 measurements, glacial hydrology, and melt modelling. However, it is not immediately evident that

16 multispectral data should be optimal for imaging glaciers and ice caps. Thus, this investigation takes an

17 inverse perspective. Taking into account spectral and radiometric properties, in situ spectral reflectance

18 data were used to simulate glacier surface response for a suite of multispectral sensors. Sensor-simulated

19 data were classified and compared. In addition, airborne multispectral imagery was classified for a range

20 of spatial resolutions and intercompared in three different ways. In these analyses, the most important

21 property which determined the suitability of a multispectral imager for glacier surface classification was

22 its radiometric range (i.e. gain settings). Low resolution imagery ( $250 \mathrm{~m}$ pixels) is too coarse to represent

23 the true complexity present on a glacier while medium resolution imagery $(60 \mathrm{~m}, 30 \mathrm{~m}$, or $20 \mathrm{~m})$

1 Present Affiliations: National Snow and Ice Data Center, University of Colorado, Boulder, Boulder, CO, USA \& Department of Earth Sciences, Dartmouth College, Hanover, NH, USA 
24 accurately represented the results derived from high resolution airborne imagery. Of those studied here,

25 the satellite imagers currently in use that are most suitable for glacier surface classification are Landsat

26 TM / ETM+ and ASTER (all with particular gain settings). Both Sentinel-2 and the OLI on Landsat 8 are

27 also expected to be similarly qualified. Landsat MSS is also found to be radiometrically well-suited for

28 glacier surface classification, but its lower spatial resolution makes it a secondary selection.

\section{Introduction}

31 The world's glaciers and ice caps (GIC), which respond much more quickly to shifting climate than the

32 continental ice sheets, provide information about past and present climate variability, are central parts of

33 the world's hydrological cycle, and are key to understanding regional and global climate change (e.g.

34 Cogley et al., 2011; Oerlemans, 1994). In addition, glaciers contribute to local biodiversity (Jacobsen et

35 al., 2012), mediate the hydrology and flooding of some mountain systems (Dahlke et al., 2012), and

36 provide crucial water resources for large populations of the world (Baraer et al., 2011; Barry, 2011;

37 Björnsson \& Pálsson, 2008; Bolch et al., 2012; Hopkinson \& Demuth, 2006).

38 Glacier surface properties are integral to the behaviour of GIC. The division of GIC into

39 accumulation and ablation areas is just the beginning of classification of glacier facies, or zones (Benson,

40 1960; Williams et al., 1991). The equilibrium line altitude (ELA) and accumulation area ratio (AAR;

41 Cogley et al., 2011) can be used as proxies for glacier mass balance (Braithwaite, 1984; Dyurgerov,

42 1996). In addition, the glacier surface controls much of a glacier's energy balance (Cuffey \& Patterson,

43 2010). Energy balance models both assimilate remotely sensed data about glacier surfaces to improve

44 their results (Machguth et al., 2009; van Angelen et al., 2012), as well as validate their results (Braun et

45 al., 2007; de Woul et al., 2006).

46 Multispectral imagery is often the best tool for studying glaciers surfaces (Pellikka \& Rees,

47 2010). Reflectance information over a range of wavelengths, good spatial resolution, frequent repeat

48 imaging, an extensive image archive, and often cost-free data access are all important. However,

49 multispectral sensors were not designed by glaciologists. Satellites like the original Landsat were (and 
50 continue to be) designed for a range of tasks including agricultural, oceanographic, and atmospheric

51 monitoring (Markham \& Helder, 2012). Therefore, it is not self-evident that they should be optimal for

52 imaging GIC. Thus, the roles that the various spectral, spatial, and radiometric properties of each sensor

53 play in the success and output of resulting classifications remain unquantified.

\section{$55 \quad$ 1.1 Research Aims}

56 Multispectral imagers are powerful tools, and with the increasing availability of a range of high quality

57 multispectral data including the recently launched Landsat 8 (Irons et al., 2012) and upcoming Sentinel 2

58 (Drusch et al., 2012), it is increasingly crucial that they are fully understood. This investigation therefore

59 takes an inverse perspective; it aims to start with in situ data to investigate the extent of information

60 available from full-spectrum data and what that means for efficient and consistent application across

61 multispectral sensors with different band capabilities and combinations. We ask the questions: How do

62 the spectral and radiometric properties of these sensors limit or enhance their performance in glacier

63 classification? Because sensors are characterised by both spatial and spectral properties, how does the

64 spatial resolution of these various sensors impact the resultant surface classification? And what does this

65 mean for glaciological applications?

66

\section{2. Background}

\section{$68 \quad 2.1$ Glacier Facies}

69 Glacier surfaces exhibit a range of zones - wet and dry, snowy and icy, clean and dirty. In order

70 to understand better the changing conditions of a glacier's surface, the area can be considered to be

71 divided into a set of systematic, idealised facies that are characterised by a particular set of properties

72 relating to the metamorphosis of the snow or ice surface; facies range from dry snow at colder, higher

73 elevations through to melting ice near the glacier terminus (Benson, 1960; Williams et al., 1991).

74 Although there is a wide range of glacier facies, a glacier can be divided into two larger regions: the

75 accumulation zone and the ablation zone. The transition between these two areas is the line of net zero 
76 annual mass change known as the equilibrium line (Cogley et al., 2011; Cuffey \& Patterson, 2010). Each

77 different configuration of facies is evidence of a different metamorphic history. Facies distributions vary

78 across glaciers both within seasons and across years, and not all facies are necessarily present on all

79 glaciers.

80 In addition, beyond these zones which are considered 'facies,' further surface classes can be

81 identified in situ and remotely. For example, there are extensive areas of wind glaze and sastrugi in

82 Antarctica (Kuchiki et al., 2011; Orheim \& Lucchitta, 1987; Scambos et al., 2012). The presence of snow

83 algae imparts a reddish tinge to an evolving wet-snow facies (Takeuchi, 2009), and dust or black carbon

84 will darken the snow surface (e.g. Painter, 2011). Debris cover on the glacier can be considered another

85 type of surface class (e.g. Casey et al., 2012; Shukla et al., 2009), as can volcanic ash deposited on glacier

86 surfaces from a nearby eruption. In this study, 'facies' are considered to be the idealised zones of glacier

87 surfaces which relate directly to accumulation and melt, while 'surface classes' are the zones which can

88 be distinguished from the surface.

89 Identification of accumulation versus ablation classes (through the ELA or the AAR) can be used

90 as a proxy for a glacier's mass balance, often in combination with further data such as a digital elevation

91 model (e.g. Braithwaite \& Müller, 1978; Dyurgerov, Meier, \& Bahr, 2009; Rabatel et al., 2005; Shea et

92 al., 2013). Also, glacier facies can be related to mass balance in other ways. Snow is bright (i.e. highly

93 reflective in much of the visible and near-infrared) and ice is darker, therefore as the melt season

94 progresses the glacier as a whole gets darker overall - specifically in proportion to the relative

95 contributions of different glacier facies. In this way, it is possible to monitor glacier albedo as a tool for

96 monitoring glacier mass balance (Dumont et al., 2012; Greuell \& Oerlemans, 2005; Greuell et al., 2007).

97 Shortwave radiation is crucial to the energy balance of a glacier. Glacier facies meaningfully

98 contribute to this radiation balance and therefore to the surface energy balance of GIC. A clear example of

99 the interrelated nature of energy balance and glacier facies can be seen in the simple parameterization of

100 the degree-day melt model where ice and snow have different degree day factors (e.g. Hock, 2003).

101 Information about the interannual and intra-annual evolution of glacier surfaces is also a key parameter in 
102 building energy balance models. Fuller consideration of glacier facies in glacier melt modelling is gaining

103 increasing traction within the glaciological community (e.g. Dumont et al., 2010; Machguth et al., 2009).

104 This is true not just for GIC, but also for the larger ice sheets, where better classification and description

105 of the unique properties of different facies improve melt model behaviour (e.g. van Angelen et al., 2012).

106 Snow and ice reflectances are heavily wavelength-dependent (e.g. Wiscombe \& Warren, 1980).

107 In particular, the NIR (near infrared, 700-1400 $\mathrm{nm}$ ) has been seen as containing quantitative information

108 about snow and ice surfaces (Kokhanovsky \& Zege, 2004; Li et al., 2001; Nolin \& Dozier, 1993). Glacier

109 facies classification, too, has focused on the NIR to the exclusion of the visible, although snow studies

110 have highlighted both ranges (Zeng et al., 1983). Sidjack and Wheate (1999) and Braun et al. (2007) cited

111 some saturation in the visible and enhanced performance in the NIR as reasons for choosing linear

112 combinations of input multispectral bands which contained large contributions from the NIR and SWIR

113 (shortwave infrared, 1400-2500 $\mathrm{nm}$ ) and minimal contributions from the visible.

114 Based on these examples, it is natural to hypothesise that sensors with enhanced capabilities in

115 the NIR will be able to classify glacier facies better than their counterparts. This belief will be

116 investigated below.

$118 \quad$ 2.2 Multispectral Remote Sensing, Classification, and Glacier Facies

119 Multispectral remote sensing images are some of the most prevalent, easily available, and

120 versatile forms of data available for the Earth Observing glaciologist. There are a variety of factors which

121 must be weighed in choosing an appropriate multispectral sensor; each separate investigation or task

122 requires an imager which is fit for purpose. Major considerations include spatial resolution, spectral

123 resolution (i.e. band wavelengths), radiometric resolution and range, temporal resolution (i.e. revisit

124 time), data cost and ease of access, length of data archive, data availability, and availability of pre-

125 processed products. From the range of different options, it is highly unlikely that any one sensor will be

126 optimal for all studies. Nevertheless, sensors were chosen to span a wide range of properties (i.e. spatial

127 scales, spectral bands, and gain settings) and priority was placed on wide use and easy data access. 
128 Although many imagers could have been included, those not included (e.g. SPOT, WorldView, etc.) will

129 be able to find analogous properties in those considered here. Figure 1 includes the range of popular and

130 prominent multispectral imagers that are considered in this study.

$132 * * *$ INSERT Figure 1 approximately here***

Glaciological uses of multispectral imagery include glacier maps and inventories (Albert, 2002;

135 Hendriks \& Pellikka, 2008; Kargel et al., 2005; Paul \& Kääb, 2005; Paul, 2000), albedo calculation

136 (Greuell et al., 2002; Knap, Reijmer, \& Oerlemans, 1999), distinguishing snow from cloud (Hall et al.,

137 1995), identification of surface and basal crevasses (Luckman et al., 2012), feature tracking (Heid \&

138 Kääb, 2012), interpolating digital elevation models (Pope et al., 2013), identifying ice sheet grounding

139 lines (Bindschadler et al., 2011), and much more (Pellikka \& Rees, 2010; Rees, 2006).

140 Classification, the process that takes quantitative information from every pixel and places each into

141 one of a group of discrete categories, is crucial for image interpretation. Many different techniques have

142 been applied to multispectral data to identify glacier surface classes. It should be noted that (automated)

143 classification of glacier extent is considered to be a separate problem, one which has been largely solved,

144 with the exception of debris-covered areas (Paul et al., 2013). Unsupervised classifications have had

145 significant success in classifying glacier facies not only because they are easily reproducible but also

146 because they are often able to exploit subtle features within data sets. ISODATA (Iterative Self-

147 Organizing Data Analysis; e.g. Aniya et al., 1996; De Angelis et al., 2007; Nolin \& Payne, 2007; Sidjak

148 \& Wheate, 1999; Wolken et al., 2009) and k-means classification (e.g. Barcaza et al., 2009; König et al.,

149 2004) are the most widely and easily implemented clustering algorithms for glacier surface classification.

150 This study will therefore implement these two iterative, unsupervised classification techniques.

\section{$152 \quad$ 2.2.1 Impact of Spatial Resolution on Multispectral Classification}


Data is not bad or good because of coarse or fine resolution, but difference scale imagery is better

154 or worse suited to particular applications. Coarse imagery often confounds land cover classification as a

155 result of pixels representing a mixture of classes. In this case, increasing resolution would increase

156 classification success. Resolution effects have been investigated in a range of different applications

157 (Baker et al., 2013; Battersby et al., 2012; Michishita et al., 2012; Phinn et al., 2012; Sobrino et al., 2012).

158 The results of these comparisons have shown that agreement between spatial scales varies depending on

159 the type of surface and the scale of inhomogeneity. In other words, although it is not immediately

160 intuitive, increasing spatial resolution can decrease classification success. This happens in the case where

161 coarser imagery serves to smooth out spatial inhomogeneity within classes.

162 To the authors' knowledge, no study has directly considered this subject for glaciers. Previous

163 studies have used higher resolution imagery $(\sim 10$ and $\sim 1 \mathrm{~m})$ to assess the accuracy of glacier extent

164 measurements using medium resolution ( $30 \mathrm{~m})$ imagery (Paul, 2000; Paul et al., 2013). There is no

165 significant difference in measured glacier area using imagery at $60 \mathrm{~m}$ resolution and finer; lower

166 resolution imagery was not tested (Paul et al., 2002). In glacier albedo calculations, the scale of albedo

167 variations is smaller than 30 m Landsat pixels (Reijmer et al., 1999), but because albedo can vary within

168 facies this does not necessarily mean glacier facies vary on the same scales. Albedo variations within

169 facies would then confound glacier surface classifications with spatial resolution finer than $30 \mathrm{~m}$.

\section{3. Field Sites and Data}

\section{$172 \quad 3.1$ Field Spectra}

173 For this study, visible through shortwave infrared $(350-2500 \mathrm{~nm})$ hemispherical-directional

174 reflectances (HDRs; Schaepman-Strub et al., 2006) were collected during two field campaigns. In August

175 2010, data were collected on Midtre Lovénbreen, Svalbard. In August 2011, data were collected on the

176 major western outlet of Langjökull, Iceland. These two locations were chosen so as to include sampling of

177 glaciers that had undergone different accumulation and melting histories. Additional differences were

178 introduced by the springtime eruption of Grímsvötn volcano in Iceland. The data, as well as consideration 
179 of available snow and ice spectral reflectance measurements and modelling efforts, are fully presented in

180 Pope and Rees (In Press) and are also available upon request to the corresponding author.

\section{$182 \quad 3.2$ Multispectral Imagery}

183 Imagery collected with the UK Natural Environment Research Council (NERC) Airborne Research

184 and Survey Facility's (ARSF) Airborne Thematic Mapper (ATM) was used to investigate the effects of

185 spatial resolution. The ATM was designed to mimic many of Landsat 7 ETM+'s bands but with added

186 spectral coverage and spatial resolution (30 vs. 2 m, determined by flight height and processing; see

187 Figure 1).

The ARSF flew a campaign over Midtre Lovénbreen on 9 August 2003 (see Figure 2); the ATM

192 was mounted inside the ARSF's Dornier 228 aircraft. Simultaneously collected laser ranging data (Rees

$193 \&$ Arnold, 2007) were used to orthorectify the imagery. Azgcorr version 5.0.0, produced by Azimuth

194 Systems UK and provided by the ARSF, was used to perform the orthorectification (Azimuth Systems,

195 2005). ATM measurements are delivered as at-sensor radiance. No measurements of incoming radiation

196 were available coincident with airborne data collection, and calibration to reflectance with pseudo-

197 invariant off-glacier targets from Landsat imagery was attempted, but no nearby surface was found to be

198 consistent in its reflectance. Therefore, ATM data were left as at-sensor radiance. No surface anisotropy

199 or slope corrections were implemented. The meteorological records at the nearby Ny-Ålesund research

200 station also indicate that the glacier surface froze overnight and that frost deposition was likely. Angular

201 crystals on the surface may increase surface reflectance (Casacchia et al., 2001). These combined effects

202 may have some impact on glacier surface classification. However, as this study is concerned mainly with

203 intercomparison of classifications at different resolutions, and the ATM image is only compared to 
204 spatially degraded versions of itself, possible classification-confounding factors will be self-consistent

205 and therefore should not impact the results of this study.

207 4. Methods

208 4.1 Spectral Response Matching

209 A narrow to broadband (NTB) conversion is necessary to use spectral reflectance to replicate

210 multispectral reflectance. This is done with a known relative spectral response function for each band

211 obtained via NASA, ESA, and the NERC Field Spectroscopy Facility. Sentinel-2 and OLI are both

212 approximated with "top hat functions" (i.e. uniform spectral response across each band), as no further

213 data were available. In addition, spectra are not used to simulate Landsat-8 OLI data because calibration

214 values were not available at the time of writing. The 12 bit radiometric resolution of the OLI is assessed

215 by comparing the effect of radiometric resolution on the full-spectrum data. In addition, only MODIS

216 bands 1-16 are considered because higher bands are in unsuitable wavelengths (e.g. water absorption) and

217 their spectral response functions were not available. More detail on spectral response matching is

218 available in the supplementary material.

\section{$220 \quad 4.2$ Multispectral Sensor Radiometric Properties}

221 Beyond the NTB conversion, further calibration parameters from each multispectral band must be taken

222 into account to fully simulate the measurements which would be taken by a multispectral sensor - had the

223 user been holding an extremely portable version of a satellite rather than a FieldSpec's photodiodes. Full

224 details on how field data were used to simulate sensor radiometric properties are available in the

225 supplementary material.

\section{4.3 Principal Component Analysis}

228 The spectra measured in this study are highly multidimensional data, and multispectral data have a

229 number of dimensions (in this case, bands) themselves. That is to say, each data "point" is characterised 
230 by many values rather than a single number. Therefore, some method is needed to reduce the

231 dimensionality of the data for analysis - without losing important information - in order to understand

232 what the most important input wavelengths are for glacier surface classification. Concisely put, PCA is a

233 transformation that reduces the dimensionality of a dataset by reprojecting it into a new coordinate space

234 (e.g. Boresjö Bronge \& Bronge, 1999; Sidjak \& Wheate, 1999). Thus, each principal component (PC) is a

235 linear combination of the input data.

236 The first two or three PCs produced from full-spectrum reflectance can be used to create

237 transferrable linear combinations (LCs) which are optimised for particular satellite bands for glacier

238 surface using appropriate relative response functions (Pope \& Rees, In Press). Here, PCs were calculated

239 separately for Langjökull and Midtre Lovénbreen field spectra, and coefficients were rounded and

240 compared. This has two benefits: one, it aids in a conceptual understanding of what each LC is

241 emphasizing within the data; two, it facilitates wider transferability of LCs by not being specifically

242 tailored to the field data. A unified set of LCs was produced for each satellite for later analysis (see

243 below). For glaciers, LC1 is representative of VNIR albedo, LC2 emphasizes the difference in reflectance

244 at blue / green wavelengths and red / NIR wavelengths, and LC3 highlights the difference in blue / NIR

245 reflectance and green / red reflectance. All LCs are available in the supplementary material. LC1 in each

246 case is representative of VNIR albedo, LC2 emphasizes the difference in reflectance at blue / green

247 wavelengths and red / NIR wavelengths, and LC3 highlights the difference in blue / NIR reflectance and

248 green / red reflectance. All LCs are available in the supplementary material.

\section{$250 \quad 4.4$ Classification}

251 Both ATM data and LCs are clustered using very similar techniques. Following previous studies

252 (Braun et al., 2007; de Woul et al., 2006; Pope \& Rees, In Press), an arbitrary number of classes were

253 identified with a clustering algorithm, ISODATA for ATM data and k-means for LCs, respectively. For

254 ATM imagery, output classes were subsequently grouped into accumulation and ablation areas for

255 statistical analysis. For LCs, grouped classes are discussed below. 


\subsection{Statistical Classification Comparison}

This study requires that two main classification accuracy assessments be conducted. The first is a clustering analysis where the classification of field spectra is compared to knowledge from fieldwork. The

260 second compares the results of classification of ATM imagery degraded to different spatial resolutions. A

261 contingency matrix is created which shows the number of times (i.e. number of pixels or number of

262 spectra) where two classifications agree or disagree. This matrix provides information on errors of both

263 omission and commission and is the basis for statistical analysis (Congalton \& Green, 1999; Congalton,

264 1991; Foody, 2002; Rees, 2008).

265 From the information in the contingency matrix, the most basic statistic is " $A$," or the overall

266 accuracy agreement. This is the sum of the times for which the classifications agree divided by the total

267 number of samples. Put another way, $A$ is the trace of the normalised contingency matrix (Rees, 2008).

268 However, random chance can lead to agreement of classes, and therefore $A$ can overestimate classification 269 accuracy.

270 In response, Cohen's Kappa ( $K$, Cohen, 1960) is a statistic which accounts for random effects

271 within the classification comparison and remains an indexed value (i.e. perfect agreement result in $K=1$ ).

272 In this way, $K$ reduces the overestimation of classification success included in $A . K$ values can also be

273 described by qualitative descriptions rather than simply numerical values (Monserud \& Leemans, 1992).

\section{5. Results \& Interpretation}

This study aims to answer the question of what qualities define the best multispectral imagers for

277 glacier surface classification. Therefore, this section begins with spectral and radiometric considerations,

278 transitions to an investigation of the impact of spatial resolution, and then combines the two to understand

279 the advantages and limitations of a range of popular multispectral sensors to glacier surface classification.

$281 \quad 5.1$ Impact of Spectral and Radiometric Properties on Glacier Surface Classification 


\subsubsection{Midtre Lovénbreen Clustering and Classification Analysis}

For this study, Midtre Lovénbreen provides an example of a largely “clean” and simple glacier.

284 LCs 1, 2, and 3 are calculated for each sensor; all cases are described in Table 1 and presented in Figure

285 3. The data were merged into three larger groups defined as snow surfaces, ice surfaces, and wet surfaces;

286 these three main classes are circled in Figure 3a. Classification success is assessed, and the results

287 presented in Table 1 are ranked in order of descending $K$.

***Insert Table 1 and Figure 3 approximately here***

Overall, all sensors in all settings are largely able to classify the three clusters. Even the worst case

292 attains almost $80 \%$ success and is considered "very good." This success is tempered by the fact that the

293 classification task is idealistically easy because there are no pixels as there would be in real imagery.

294 There is one setup which does not group the wet classes as well as the other sensors: MODIS using bands

2958 and higher in a low gain setting (Figure 3o). This is possibly due to lack of contributions to the LCs

296 from NIR wavelengths.

297 Radiometric resolution on its own does not appear to be important in the "clean glacier" case on

298 Midtre Lovénbreen, as can be seen by comparing Figures 1a, 1d, 1e, and 1c which are all clustered using

299 full spectra but at unrestricted, 16 bit, 12 bit, and 8 bit resolution, respectively. However, when combined

300 with a limited set of bands to use in LCs, the quantisation does begin to appear (e.g. Equations 11 and 12

301 in the supplementary material used to produce Figures 1g and 1i, emulating ASTER). This example

302 supports the importance of using LCs with a higher number of band combinations which better represent

303 the full spectrum surface reflectance.

304 Radiometer properties (i.e. radiance range and gain settings) do appear to play some role in

305 classification accuracy, but it is hard to assess fully with such widespread success for the Midtre

306 Lovénbreen spectra. Saturation is clearly visible in some Landsat settings; its distinctive signature is a

307 linear alignment of spectra with high LC1 values for Landsat TM/ ETM+ HHHH (i.e. high gain for Bands 
309 spectra biplots better than Landsat LLLL (i.e. low gain for Bands 1-4; Figures 1k and 1p, respectively),

310 which makes sense given the high to lower reflectance transition of glacier surfaces from visible to NIR

311 wavelengths. Interestingly, ASTER in a high gain setting (Figure 3b) appears to have such success in

312 classification because all of the bright, snowy surfaces were compressed into the same saturated point in

313 the plot, thereby making the entire class almost entirely homogeneous.

314 Ultimately, while varying slightly in performance, imager radiometric properties do not provide

315 significant limitations or guidance in selecting the most appropriate multispectral imager for surface

316 classification of clean glaciers.

\section{$318 \quad$ 5.1.2 Langjökull Clustering and Classification Analysis}

319 Langjökull provides an example of a glacier with a more complex set and larger range of surface

320 classes, furnished in this case by ash from the Grímsvötn eruption in spring 2011. For Langjökull spectra,

321 a very similar analysis to Midtre Lovénbreen is performed. All cases are described in Table 2 and

322 presented in Figure 4. However, the results were merged into only two classes (clean ice and other; this is

323 indicated by the circle in Figure 4a). Again, classification is assessed using knowledge from fieldwork,

324 and the results are presented in Table 2 ranked in order of descending $K$.

325

***Insert Table 2 and Figure 4 approximately here***

While the "clean" glacier ice was easily classified across all sensors, and despite the apparently

329 simpler task of dividing into two groups rather than Midtre Lovénbreen's three, there is a much larger

330 range of success between sensors and settings for the Langjökull spectra. For the ash-covered glacier, no

331 imager emulation is fully able to represent the range of information contained in the full spectrum data.

332 From the spread of data points, it appears this is largely due to lack of sensitivity in LC2, although 
333 saturation in LC1 also plays a role. Nevertheless, because of the simpler task (i.e. identifying clean ice), it

334 is possible to achieve "perfect" classification success (for terminology see Monserud \& Leemans, 1992).

335 Radiometric resolution, again, is not found to be important on its own, but the quantising effects are

336 again seen in ASTER because of the smaller number of bands contributing to the LCs (see Figures $2 \mathrm{~g}, 2 \mathrm{i}$,

337 and to a lesser extent 2n). Even without restricting spectral range and rounding for radiometric resolution

338 only (no scaling, 16 bit, 12 bit, and 8 bit in Figures 2a, 2b, 2c, and 2d, respectively), saturation does

339 appear to be present in the data; this is because some spectra were measured at higher than $100 \%$

340 reflectance as a result of a specular component of reflectance (see Section 3.5.2).

341 Indeed, radiometric resolution is overshadowed by other factors. For example, 12 bit MODIS

342 sensors would be expected to perform well given their higher radiometric resolution compared to

343 Landsat's 8 bits. However, MODIS gain settings are tuned for darker land and ocean surfaces and so are

344 less suitable to the task of glacier surface classification. As this demonstrates, radiometric range is more

345 important than radiometric resolution.

346 The importance of radiometric range and gain settings is also demonstrated by ASTER and

347 Landsat. ASTER hi gain (Figure 4n), Landsat TM / ETM+ LLLL (Figure 4m), Landsat MSS (Figure 4h),

348 and Landsat TM / ETM+ HHHH (Figure 4k) all show a linear feature influencing the higher ranges of

349 both LC1 and LC2, the result of "sensor" saturation. This is more pronounced for ASTER than Landsat

350 because more contributing "bands" are saturated, and LC2 shares more coefficients in common with LC1

351 for ASTER. Landsat MSS is actually very similar to Landsat TM / ETM+ HHHH, but Landsat LLLH

352 performs better than other Landsat setups. For ASTER, as in the Midtre Lovénbreen case, the brightest

353 classes (New Drifted Snow 1, New Drifted Snow 3, and White Ice 2) are compressed to a single point.

354 The LC1-LC2 biplots for MODIS 8+ in both gain settings (Figure 4o and p) demonstrate an

355 intriguing chevron shape. Various theories were considered for why this would occur, including lack of

356 band representation in the NIR or perhaps particular placement of bands in higher and lower wavelengths

357 causing anomalous effects in LC2. In order to find the real culprit, it is necessary to return to exactly what

358 LC1 and LC2 are (see Equations 26 and 17 in supplementary material). Unlike for other bands, the 
359 magnitude of all coefficients of bands contributing to the LCs for MODIS 8+ are identical, except for a

360 flip in sign for higher bands. Where reflectance in Bands 8 to 12 is much higher than 13 to 16 , there is a

361 positive linear pattern, and when the opposite is true there is a negative linear pattern. The linear pattern is

362 more pronounced than it would be otherwise because snow and ice spectra have fairly uniform reflectance

363 across the range of wavelengths observed by Bands 8 to 16. Although PCs are uncorrelated, rounding in

364 the coefficients of the LCs caused an artefact in this case.

365 Ultimately, as can be seen with the $K$ rankings in Table 2, while a large number of sensors do a

366 "perfect" job identifying clean ice on Langjökull, others perform very poorly. There is a pronounced

367 division between the two, jumping from $K=0.9081$ for ASTER normal gain down to 0.6579 for MODIS

368 1-7. It should be noted that these results hold only for a simple unsupervised classification; supervised or

369 iterative approaches have the potential to yield more specific classes but would lose transferability and

370 ease of implementation. For surface classification of "dirty" or ash-covered glaciers, these results indicate

371 that sensors with "Good," "Fair," or "Poor" $K$ values should be foregone in preference for the many

372 alternative sensors which rank higher in performance.

373

$374 \quad 5.2$ Impact of Spatial Resolution on Glacier Surface Classification

$375 \quad$ 5.2.1 Experimental Strategy and Considerations

376 ATM imagery of most of Midtre Lovénbreen was used in this experiment. LCs were calculated for

377 the $2 \mathrm{~m}$ imagery (Equations 8 and 9 in supplementary material), and the image is masked using a manual

378 outline of the glacier. LCs were degraded to 20, 30, 60 and $250 \mathrm{~m}$ pixels analogous to Sentinel-2, Landsat

379 TM / ETM+ / OLI, Landsat MSS, and MODIS Bands 1-2, respectively; 500 m imagery is considered too

380 coarse to resolve smaller mountain glaciers. LCs were then input into an ISODATA classification (10

381 classes, maximum 10 iterations, 95\% convergence); output classes were merged by the user into

382 meaningful glaciological classes (i.e. ablation and accumulation facies).

383 As spatial resolution is varied, the radiometric content of all images remains constant as a control.

384 As alluded to earlier, the impact of resolution will depend on the fractal scale of the surfaces being 
considered. For this purpose, Midtre Lovénbreen is taken to be a representative glacier surface because

386 there is no reason to believe otherwise. Most classification accuracy and quality assessments suffer from

387 their inability to fulfil some assumptions, namely co-registration and random sampling (e.g. Comber,

388 Fisher, Brunsdon, \& Khmag, 2012); this experiment uses all pixels to assess accuracy, and because

389 coarser imagery is created from finer imagery, co-registration is a not an issue.

390 By definition, the detail available in the $2 \mathrm{~m}$ results will be blurred out (to the lower resolution), but

391 it is unknown what beneficial or detrimental effects this may have on surface classification accuracy and

392 what this will mean for individual sensors which provide imagery at a variety of spatial resolutions. In

393 this case, only pixel-based classification is considered because pixel-based classifications have been

394 traditionally easier to implement with a range of software tools. Although object-based image analysis has

395 been shown to have benefits for very-high resolution imagery $(1 \mathrm{~m})$, at any lower resolutions it does not

396 produce statistically significantly different results from pixel-based classification (Baker et al., 2013).

\subsubsection{Spatial Resolution Assessment 1}

For each resolution, the ISODATA classification outputs 10 classes (see Figure 5). Classes 1 and 2

400 are mixes of shadow and thin debris cover, classes 3 through 8 are interpreted as ablation classes, and

401 classes 9 and 10 are interpreted as accumulation classes. For reasons described in earlier sections

402 concerning the potential presence of frost and the use of radiance rather than reflectance, from

403 investigation of the visible imagery it appears this interpretation (i.e. merging of classes) may slightly

404 overestimate the accumulation area. Nevertheless, this is deemed to be preferable to significant

405 underestimation of the area of accumulation facies.

406 Percentages of each class and the aggregated accumulation and ablation areas are presented in

407 Table 3. Most classifications have very similar accumulation and ablation area measurements, with the

408 exception of the $250 \mathrm{~m}$ pixel classification, which results in slightly less ablation and more accumulation,

409 although the differences are below 5\%. While these figures agree, that does not mean the classification

410 results agree on the pixel level; to understand this, further analysis is necessary. 


\section{$414 \quad$ 5.2.3 Spatial Resolution Assessment 2}

415 To begin to understand pixel-level agreement of glacier surface classification at various resolutions, 416 a majority filter was used to down-sample high resolution images to lower resolutions (see Table 4).

417 Because class numbers are not indicative mathematically of their similarity or difference, mathematic

418 convolution would not be meaningful. As would be expected, similarity is the most meaningful between

419 images with similarly sized pixels (see Table 4). However, the 2 and $30 \mathrm{~m}$ images and 2 and $20 \mathrm{~m}$ images

420 are more similar than the 20 and 30 m images. While this could be the result of a resampling artefact, it

421 does indicate that medium resolution imagery is doing a good job at reproducing the results obtained with

422 high resolution imagery. The $2 \mathrm{~m}$ classification results are approximately as similar to the $60 \mathrm{~m}$ results as

423 all of the medium resolution classifications are to each other, potentially indicating that 20 or $30 \mathrm{~m}$

424 imagery is more suited to glacier surface classification than $60 \mathrm{~m}$ resolution imagery. At the bottom, the

425 low resolution imagery (250 m pixels) by a large step shows the lowest agreement with all other results;

426 according to this result, MODIS imagery is not appropriate for glacier surface classification.

427 The $A$ and $K$ rankings of the classification comparisons differ slightly in the relative position of the 428 comparison of $60 \mathrm{~m}$ and higher resolution results, $250 \mathrm{~m}$ to $2 \mathrm{~m}$ and $20 \mathrm{~m}$ images. The inferences drawn 429 above are consistently supported by both $A$ and $K$, but divisions are more visible in the $K$ values than in 430 the $A$ values. This lends some confidence to the conclusions, because $K$ values should contain more signal 431 and less false agreement than $A$ values.

\section{$435 \quad$ 5.2.4 Spatial Resolution Assessment 3}


In addition to downscaling high resolution imagery, the low resolution imagery is resampled to

437 high resolution by converting each pixel in the high resolution image to a host of small pixels of the same

438 class (i.e. one $250 \mathrm{~m}$ pixel becomes 15,625 corresponding $2 \mathrm{~m}$ pixels). Pixels in the original high

439 resolution and the down-sampled classifications are compared and assessed using $A$ and $K$ (see Table 5).

$440 A$ and $K$ ranks and relative values are in better agreement than in the previous section. For this round of

441 comparisons, similarity in pixel size was the unambiguous driver of similarity in results. Again, there is a

442 clear break between high (2 m) / medium (20,30, or $60 \mathrm{~m})$ resolution image results and any comparison

443 to the $250 \mathrm{~m}$ resolution classification results.

$445 \quad * * *$ Insert Table 5 approximately here***

\section{Discussion}

Using full-spectrum in situ reflectance data to emulate the spectral and radiometric properties of a

449 range of imagers and settings is a controlled experiment of sorts, removing uncertainty introduced by

450 unknown or changing surface conditions. For both clean and dirty glacier surfaces, although radiometric

451 resolution is largely insignificant, selecting the sensor / gain settings with the most appropriate

452 radiometric range is very important. For the data presented here, Landsat TM / ETM+ LLLH, Sentinel-2,

453 Landsat MSS, ASTER low 1, and ASTER normal perform the classification tests the best. The

454 radiometric properties of the recently-launched OLI were not available at the time of writing, but by

455 considering analogues for its spectral bands and radiometric resolution, it is possible to envision that it

456 would yield results which are a cross between full-spectrum 12 bit results, Sentinel-2, and Landsat TM /

457 ETM+ and would therefore be quite well suited to glacier surface classification, too.

458 Moving on to spatial resolution, each method used to compare glacier surface classification at

459 different pixel sizes gives a slightly different impression of the importance of sensor spatial resolution.

460 Figure 5 clearly shows the loss of detail associated with observation at lower resolutions, but the relative

461 area of shadow, debris, accumulation and ablation facies is very similar among images of all classes. 
462 However, relative accuracy at different spatial scales is dependent on the scale of inhomogeneity within

463 and between classes. For Midtre Lovénbreen, classes appear to be similarly behaved at high and medium

464 resolutions, but the glacier is definitely more complex than $250 \mathrm{~m}$ pixels can capture. Although $15 \mathrm{~m}$

465 pixels (analogous to ASTER bands or fused ETM+ images) are not explicitly considered, in view of these

466 results, such an analysis would appear to have been superfluous. Based upon this analysis, for glacier

467 surface classification, high resolution imagery would indeed be desirable. It appears that even the highest

468 resolution that MODIS is capable of providing $(250 \mathrm{~m})$ is insufficient for glacier surface classification.

469 Medium resolution imagery is found to be adequate for the task, and 20 or $30 \mathrm{~m}$ imagery is preferable to

47060 m imagery but not drastically.

471 However, it is important to question how representative the surfaces of Langjökull (spectrally) and

472 Midtre Lovénbreen (both spectrally and spatially) are of glaciers in general. The selection of field spectra

473 sampling locations was based upon the exploration of the field party. For Midtre Lovénbreen, the glacier

474 is small and therefore it is highly unlikely that any major classes were omitted. Langjökull is much larger,

475 and measurements were limited to a single outlet. Nevertheless, Landsat classification of this outlet

476 indicates the presence of the full range of facies along the transect which was used, and therefore it is

477 unlikely that any major classes were omitted there, either.

478 The question then turns to the relative proportion of each class as measured; to an extent, it is

479 important to recognize that these relative proportions will have some impact on the statistics, in particular

480 the proportions in any contingency table. The ranking of sensors according to $K$ values could conceivably

481 have been more impacted by different proportions of facies. For example, for Midtre Lovénbreen,

482 inclusion of more 'coarse snow' and 'dry ice' spectra would likely have depressed all $K$ values. Similarly,

483 for Langjökull, including more spectra from the classes near the 'white ice' spectra could have had a

484 similar impact. However, although the magnitude of the statistics would have changed, this would have

485 impacted (beneficially or detrimentally) all simulated clustering analyses, and it is therefore unlikely that

486 the conclusions thereof (based on relative rank) would change. This study based conclusions on all 
available data, choosing not to filter out spectra. Nevertheless, potential impacts of relative proportions of

488 classes would be testable with further sampling campaigns.

489 It is crucial for this study that the spectra measured on Midtre Lovénbreen and Langjökull (and

490 principal components thereof) are considered to be representative of other glaciers. Because spectra are a

491 result of a combination of physical processes (snow formation, accumulation, compaction, melt, etc.), it is

492 reasonable to expect that this will be the case. Indeed, the similarity of the first and second principal

493 components of spectra between the two glaciers supports this interpretation. In addition, preliminary

494 principal component analysis of satellite imagery from other glaciers at other times yield nearly identical

495 principal component band combinations. Indeed, for a particular glacier, if the user wanted a customised

496 band combination, it would be reasonable to use PC1 and PC2 of a site-specific PCA. Thus, because

497 spectra from the two chosen field sites and satellite images from others agree upon the principal

498 components, it is reasonable to assume that Midtre Lovénbreen and Langjökull are representative glaciers 499 for study.

$500 \quad$ Nevertheless, although the major classes of Midtre Lovénbreen and Langjökull will be spectrally

501 representative of many glaciers, there are still surface features on other subsets of glaciers that are not

502 considered but could and would impact transferability of results. The largest subset of glaciers will be

503 those in colder climates, in particular those with dry snow facies, for example in Greenland and

504 Antarctica. Other surfaces which fall outside the remit of this study include those influenced by debris

505 cover, dust, black carbon, and snow algae. It is entirely possible that the LCs presented here will be

506 appropriate for classification of these facies; earlier work (Boresjö Bronge \& Bronge, 1999) classified

507 snow and ice zonation in Antarctica (even including sea ice) using PCA as a guide. More work will be

508 needed to confirm or deny this hypothesis, but that is beyond the scope of this study.

509 The analysis of the impact of spatial resolution on classification success raises the question of

510 whether Midtre Lovénbreen is also spatially representative of other glaciers. Processes which impact the

511 spatial distribution and scale of facies include the accumulation distribution, wind and avalanche

512 redistribution, melt patterns, and local slopes, to name a few. In these regards, there is nothing that sets 
513 Midtre Lovénbreen apart as a special glacier. By contrast, factors such as crevasses or incised supraglacial

514 streams are glacier-specific and may have some impact on the impact of resolution on surface

515 classification. However, such features are small on Midtre Lovénbreen and would likely manifest

516 themselves as an important difference between high- and mid-resolution images, rather than influencing

517 the conclusion that low-resolution images are inappropriate for facies classification. Thus, while there is

518 no reason to suspect that Midtre Lovénbreen would have a different spatial character than other glaciers,

519 it is recognized as a limitation of this study. Investigation of a wider study area would confirm or confine

520 this extrapolation, so it is suggested as a potential future research direction.

521 Accepting the transferability of this study, efficient and effective multispectral glacier surface

522 classification has many implications for glaciological research. The most immediate use is selection of

523 optimal imagery for widespread measurements of AAR (and therefore ELA) as mass balance proxies (e.g.

524 Rabatel et al., 2008; Rabatel et al., 2005; Shea et al., 2013). Some of the studies upon which the

525 classification method developed in this thesis were used for validation of glacier melt and hydrology

526 models (Braun et al., 2007; de Woul et al., 2006). The effective identification of wet facies on clean

527 glaciers by a wide range of sensors predisposes this classification scheme to effective application to

528 hydrological applications. Increased application to validate models studying glacier surface hydrology

529 would therefore be appropriate. In addition to small mountain glaciers (e.g. Dahlke et al., 2012), there is

530 increasing interest in water-saturated areas in Greenland, so this may be a promising research direction. In

531 addition, energy balance models may find some overlap with hydrological modelling, driving the liquid

532 contributions to the glacier system. This study provides another step in the direction of successfully

533 applying such an assimilation or validation mechanism.

534 Other areas of research which will be impacted eventually include, as mentioned earlier, studies

535 of climate variability, understanding of water resources, study of geomorphologic hazards, and

536 investigation of high altitude and latitude biodiversity. These all tie back to better process-based

537 understanding of glacier surface processes enabled by application of multispectral remote sensing. Here,

538 two data sets were used to investigate the wider application of glacier surface classification across many 
539 platforms. For the new sensors whose properties are not fully quantified (OLI on Landsat 8 and Sentinel-

540 2), it will be interesting to confirm the conclusions drawn here from the assumptions made here. Further

541 principal component analysis of multispectral remote sensing imagery of glaciers would confirm the

542 linear combinations of bands presented here for surface classification.

543 In addition, the transferability of the conclusions about the necessity of medium-to-high spatial

544 resolution has wide implications. It is pragmatic and efficient to identify the lowest reasonable resolution

545 of data to use for studying glacier surface properties. This is especially true if the techniques are going to

546 be used across wide areas or long time series. Although not expected that the conclusions will change

547 significantly, it would still be beneficial to confirm with ATM images from other glaciers, in other areas,

548 and across larger areas as well. Beyond application of ATM images, coordinated campaigns allowing for

549 intercomparison of coincident, multi-resolution data would lead to even more robust conclusions in the

550 future.

551

\section{7. Conclusion}

553 Increasing availability of multispectral data requires that researchers know what data types are best suited

554 for their own research questions. For glacier surface classification, the radiometric, spectral, and spatial

555 properties of a suite of popular sensors (ATM, ASTER, MSS, TM, ETM+, OLI, Sentinel-2, and MODIS)

556 are investigated using data sets in common to perform controlled analyses. Linear combinations for all

557 sensors were created based on principal component analysis of in situ spectra. Among these sensors,

558 spectral resolution and range or radiometric resolution were not important on their own. The most

559 important property which determined the suitability of a multispectral imager for glacier surface

560 classification was its radiometric range. In particular, it was found to be beneficial to have a low gain in

561 the visible and a higher gain in the NIR.

562 Spatial resolution can, seemingly paradoxically, be either beneficial or detrimental to classification,

563 depending on the fractal scale of the surface being classified. For glaciers, it was found that low

564 resolution imagery ( $250 \mathrm{~m}$ pixels) is too coarse to represent the true complexity present on a glacier. 
565 However, medium resolution imagery $(60 \mathrm{~m}, 30 \mathrm{~m}$, or $20 \mathrm{~m})$ did accurately represent the results derived

566 from high resolution airborne imagery. Nevertheless, $30 \mathrm{~m}$ imagery was preferable to $60 \mathrm{~m}$ imagery.

567 From this, it was inferred that inhomogeneity on glaciers is significant on a scale between $\sim 60$ and $250 \mathrm{~m}$.

568 Based upon these radiometric, spatial, and spectral requirements, the sensors emulated here that are

569 most suitable for glacier surface classification are Landsat TM / TM+ (with gain settings of LLLH) and

570 ASTER (low 1 or normal gain). Both Sentinel-2 and the OLI on Landsat 8 are also expected to be

571 similarly qualified. Landsat MSS is also found to be radiometrically well-suited for glacier surface

572 classification, but its lower spatial resolution makes it a secondary selection. However, MSS has historical

573 imagery whereas other sensors have more recent (or future) data ranges, and therefore these imagers

574 could be used in conjunction with each other. This demonstrates, once again, that although priority can be

575 given to sensor capabilities, temporal resolution and data availability will still remain important

576 considerations.

577 Consideration was given to the transferability of the results presented here. The result of universal

578 physical processes, Midtre Lovénbreen and Langjökull are deemed to be representative of the classes

579 present on many GICs, both spatially and spectrally. Future work should focus on downstream impacts,

580 related to mass balance proxies, integrated with glacier modelling, and related to applied studies of glacier

581 behaviour. The potential exists for further confirmation of the conclusions presented here using further

582 data sets.

583 In sum, the work presented in this paper has contributed to the understanding of glaciological

584 applications of multispectral remote sensing imagery, a field which will be sure to remain innovative and

585 vital to glaciology for many years to come.

586 Acknowledgements

587 A. Pope was supported by the National Science Foundation Graduate Research Fellowship Programme

588 under Grant No. DGE-1038596. Further research support came from UK Natural Environment Research

589 Council's Field Spectroscopy Facility, ARCFAC (the European Centre for Arctic Environmental

590 Research), Trinity College Cambridge, Sigma Xi, the Norwegian Marshall Fund, the Explorers Club, the 
591 National Geographic Society Young Explorers Program, the Scott Polar Research Institute, the

592 Cambridge University Geography Department, the Cambridge University Department of Anglo-Saxon,

593 Norse, and Celtic Studies, and the Cambridge University Worts Fund. The thank the creators and

594 development teams of the freely available software used in this research, including ImageJ

595 (http://rsb.info.nih.gov/ij/), MultiSpec (https://engineering.purdue.edu/ biehl/MultiSpec/), QuantumGIS

596 (http://www.qgis.org/), Plot (http://plot.micw.eu/), and Zotero.

597 The authors would also like to acknowledge the support of the staff of Norwegian Polar Institute's

598 Sverdrup Station in Ny-Ålesund and Addi Hermannsson and Ice, Ltd. for logistical support on Langjökull

599 and field assistance from Alexandra Giese, Richard Morris, and Jon Peatman.

600 


\section{References}

602 Albert, T. H. (2002). Evaluation of Remote Sensing Techniques for Ice-Area Classification Applied to the 603 Tropical Quelccaya Ice Cap, Peru. Polar Geography, 26, 210-226.

604 Aniya, M., Naruso, H., Skvarca, P., \& Casassa, G. (1996). The use of satellite and airborne imagery to 605 invesntory outlet glaciers of the Southern Ratagonia Icefield, South America. Photogrammetric $606 \quad$ Engineering and Remote Sensing, 62(12), 1361-1369.

607 Azimuth Systems. (2005, July). AZGCORR Users Manual. Retrieved from

608 http://arsf.nerc.ac.uk/documents/azgcorr_v5.pdf

609 Baker, B. A., Warner, T. A., Conley, J. F., \& McNeil, B. E. (2013). Does spatial resolution matter? A 610 multi-scale comparison of object-based and pixel-based methods for detecting change associated with gas well drilling operations. International Journal of Remote Sensing, 34(5), 1633-1651.

613 Baraer, M., Mark, B. G., McKenzie, J. M., Condom, T., Bury, J., Huh, K.-I., ... Rathay, S. (2011).

614 Glacier recession and water resources in Peru's Cordillera Blanca. Journal of Glaciology, $615 \quad 58(207), 134-150$.

616 Barcaza, G., Aniya, M., Matsumoto, T., \& Aoki, T. (2009). Satellite-derived equilibrium lines in 617 Northern Patagonia Icefield, Chile, and their implications to glacier variations. Arctic, Antarctic, 618 and Alpine Research, 41(2), 174-182.

619 Barry, R. G. (2011). The cryosphere - past, present, and future: a review of the frozen water resources of 620 the world. Polar Geography, 34(4), 219-227. doi:10.1080/1088937X.2011.638146

621 Battersby, S. E., Hodgson, M. E., \& Wang, J. (2012). Spatial Resolution Imagery Requirements for 622 Identifying Structure Damage in a Hurricane Disaster: A Cognitive Approach. Photogrammetric 623 Engineering and Remote Sensing, 78(6), 625-635.

624 Benson, C. S. (1960). Stratigraphic studies in the snow and firn of the Greenland ice sheet (PhD).

625 California Institute of Technology, Pasadena, California. Retrieved from

626 http://etd.caltech.edu/etd/available/etd-03232006-104828/ 
627 Bindschadler, R., Choi, H., Wichlacz, A., Bingham, R., Bohlander, J., Brunt, K., ... Young, N. (2011).

628 Getting around Antarctica: new high-resolution mappings of the grounded and freely-floating 629 boundaries of the Antarctic ice sheet created for the International Polar Year. The Cryosphere, $630 \quad 5(3), 569-588$.

631 Björnsson, H., \& Pálsson, F. (2008). Icelandic Glaciers. Jökull, 58, 365-386.

632 Bolch, T., Kulkarni, A., Kääb, A., Huggel, C., Paul, F., Cogley, J. G., ... Stoffel, M. (2012). The State 633 and Fate of Himalayan Glaciers. Science, 336(6079), 310-314. doi:10.1126/science.1215828

634 Boresjö Bronge, L., \& Bronge, C. (1999). Ice and snow-type classification in the Vestfold Hills, East 635 Antarctica, using Landsat-TM - data and ground radiometer measurements. International Journal 636 of Remote Sensing, 20(2), 225. doi:10.1080/014311699213415

637 Braithwaite, R. J. (1984). Can the mass balance of a glacier be estimated from its equilibrium line 638 altitude? Journal of Glaciology, 30(106), 364-368.

639 Braithwaite, R. J., \& Müller, F. (1978). On the parameterization of glacier equilibrium line altitude. 640 IAHS-AISH, 126, 263-271.

641 Braun, M., Schuler, T. V., Hock, R., Brown, I. A., \& Jackson, M. (2007). Comparison of remote sensing 642 derived glacier facies maps with distributed mass balance modelling at Engabreen, northern 643 Norway. Glacier Mass Balance Changes and Meltwater Discharge, IAHS 318, 126-134.

644 Casacchia, R., Lauta, F., Salvatori, R., Cagnati, A., Valt, M., \& rb b. J. B. (2001). Radiometric 645 investigation of different snow covers in Svalbard. Polar Research, 20(1), 13-22. 646 doi:10.1111/j.1751-8369.2001.tb00035.x

647 Casey, K. A., Kääb, A., \& Benn, D. I. (2012). Geochemical characterization of supraglacial debris via in 648 situ and optical remote sensing methods: a case study in Khumbu Himalaya, Nepal. The 649 Cryosphere, 6(1), 85-100. doi:10.5194/tc-6-85-2012

650 Cogley, J. G., Hock, R., Rasmussen, L. A., Arendt, A. A., Bauder, A., Braithwaite, R. J., ... Zemp, M. 651 (2011). Glossary of Glacier Mass Balance. Paris: UNESCO-IHP. 
652 Cohen, J. (1960). A Coefficient of Agreement for Nominal Scales. Educational and Psychological 653 Measurement, 20(1), 37-46. doi:10.1177/001316446002000104

654 Comber, A., Fisher, P., Brunsdon, C., \& Khmag, A. (2012). Spatial analysis of remote sensing image 655 classification accuracy. Remote Sensing of Environment, 127, 237-246.

656 doi:10.1016/j.rse.2012.09.005

657 Congalton, R. G. (1991). A review of assessing the accuracy of classifications of remotely sensed data.

658 Remote Sensing of Environment, 37(1), 35-46. doi:10.1016/0034-4257(91)90048-B

659 Congalton, R. G., \& Green, K. (1999). Assessing the Accuracy of Remotely Sensed Data: Principles and $660 \quad$ Practices. Boca Raton, FL: Lewis Publishers.

661 Cuffey, K. M., \& Patterson, W. S. B. (2010). The Physics of Glaciers (4th ed.). London: Academic Press. 662 Dahlke, H. E., Lyon, S. W., Stedinger, J. R., Rosqvist, G., \& Jansson, P. (2012). Contrasting trends in 663 floods for two sub-arctic catchments in northern Sweden - does glacier presence matter? Hydrol. 664 Earth Syst. Sci., 16(7), 2123-2141. doi:10.5194/hess-16-2123-2012

665 De Angelis, H., Rau, F., \& Skvarca, P. (2007). Snow zonation on Hielo Patagónico Sur, Southern 666 Patagonia, derived from Landsat 5 TM data. Global and Planetary Change, 59(1-4), 149-158. 667 doi:10.1016/j.gloplacha.2006.11.032

668 De Woul, M., Hock, R., Braun, M., Thorsteinsson, T., Jóhansen, T., \& Halldorsdottir, S. (2006). Firn 669 layer impact on glacial runoff: a case study at Hofsjökull, Iceland. Hydrological Processes, 20, $670 \quad 2171-2185$.

671 Drusch, M., Del Bello, U., Carlier, S., Colin, O., Fernandez, V., Gascon, F., ... Bargellini, P. (2012). 672 Sentinel-2: ESA's Optical High-Resolution Mission for GMES Operational Services. Remote 673 Sensing of Environment, 120, 25-36. doi:10.1016/j.rse.2011.11.026

674 Dumont, M., Brissaud, O., Picard, G., Schmitt, B., Gallet, J.-C., \& Arnaud, Y. (2010). High-accuracy 675 measurements of snow Bidirectional Reflectance Distribution Function at visible and NIR 676 wavelengths - comparison with modelling results. Atmos. Chem. Phys., 10(5), 2507-2520. 677 doi:10.5194/acp-10-2507-2010 
678 Dumont, M., Gardelle, J., Sirguey, P., Guillot, A., Six, D., Rabatel, A., \& Arnaud, Y. (2012). Linking 679 glacier annual mass balance and glacier albedo retrieved from MODIS data. The Cryosphere, 6 , 680 1527-1539. doi:10.5194/tcd-6-2363-2012

681 Dyurgerov, M. (1996). Substitution of long term mass balance data by measurements of one summer. 682 Gletscherkd. Glazial geol., 32, 177-184.

683 Dyurgerov, M., Meier, M. F., \& Bahr, D. B. (2009). A new index of glacier area change: a tool for glacier 684 monitoring. Journal of Glaciology, 55(192), 710-716.

685 Foody, G. M. (2002). Status of land cover classification accuracy assessment. Remote Sensing of 686 Environment, 80(1), 185-201. doi:10.1016/S0034-4257(01)00295-4

687 Greuell, W., Kohler, J., Obleitner, F., Glowacki, P., Melvold, K., Bernsen, E., \& Oerlemans, J. (2007). 688 Assessment of interannual variations in the surface mass balance of 18 Svalbard glaciers from the 689 Moderate Resolution Imaging Spectroradiometer/Terra albedo product. Journal of Geophysical $690 \quad$ Research, 112, D07105.

691 Greuell, W., \& Oerlemans, J. (2005). Validation of AVHRR- and MODIS-derived albedos of snow and 692 ice surfaces by means of helicopter measurements. Journal of Glaciology, 51(172), 37-48.

694 Greuell, W., Reijmer, C. H., \& Oerlemans, J. (2002). Narrowband-to-broadband albedo conversion for 695 glacier ice and snow based on aircraft and near-surface measurements. Remote Sensing of $696 \quad$ Environment, 82, 48-63.

697 Hall, D. K., Riggs, G. A., \& Salomonson, V. V. (1995). Development of methods for mapping global 698 699 snow cover using moderate resolution imaging spectroradiometer data. Remote Sensing of Environment, 54(2), 127-140. doi:10.1016/0034-4257(95)00137-P

700 Heid, T., \& Kääb, A. (2012). Repeat optical satellite images reveal widespread and long term decrease in 701 land-terminating glacier speeds. The Cryosphere, 6(2), 467-478. doi:10.5194/tc-6-467-2012 
702 Helder, D. L., Karki, S., Bhatt, R., Micijevic, E., Aaron, D., \& Jasinski, B. (2012). Radiometric

703 Calibration of the Landsat MSS Sensor Series. IEEE Transactions on Geoscience and Remote

$704 \quad$ Sensing, 50(6), 2380 -2399. doi:10.1109/TGRS.2011.2171351

705 Hendriks, J., \& Pellikka, P. (2008). Semi-automatic glacier delineation from Landsat imagery over

706 Hintereisferner in the Austrian Alps. Zeitschrift für Gletscherkunde und Glazialgeologie, 41, 55-

$707 \quad 75$.

708 Hock, R. (2003). Temperature index melt modelling in mountain areas. Journal of Hydrology, 282, 104-

$709 \quad 115$.

710 Hopkinson, C., \& Demuth, M. (2006). Using airborne lidar to assess the influence of glacier downwasting

711 on water resources in the Canadian Rocky Mountains. Canadian Journal of Remote Sensing,

$712 \quad 32(2), 212-222$.

713 Irons, J. R., Dwyer, J. L., \& Barsi, J. A. (2012). The next Landsat satellite: The Landsat Data Continuity

714 Mission. Remote Sensing of Environment, 122, 11-21. doi:10.1016/j.rse.2011.08.026

715 Jacobsen, D., Milner, A. M., Brown, L. E., \& Dangles, O. (2012). Biodiversity under threat in glacier-fed

716 river systems. Nature Climate Change, 2(5), 361-364. doi:10.1038/nclimate1435

717 Kargel, J. S., Abrams, M. J., Bishop, M. P., Bush, A., Hamilton, G., Jiskoot, H., .. Wessels, R. (2005).

718 Multispectral imaging contributions to global land ice measurements from space. Remote Sensing

719 of Environment, 99(1-2), 187-219. doi:10.1016/j.rse.2005.07.004

720 Knap, W. H., Reijmer, C. H., \& Oerlemans, J. (1999). Narrowband to broadband conversion of Landsat

721 TM glacier albedos. International Journal of Remote Sensing, 20(10), 2091-2110.

722 Kokhanovsky, A. A., \& Zege, E. P. (2004). Scattering Optics of Snow. Applied Optics, 43(7), 1589-1602.

723 doi:10.1364/AO.43.001589

724 König, M., Winther, J.-G., Kohler, J., \& König, F. (2004). Two methods for firn-area and mass-balance

725 monitoring of Svalbard glacier with SAR satellite images. Journal of Glaciology, 50(168), 116-

$726 \quad 128$. 
727 Kuchiki, K., Aoki, T., Niwano, M., Motoyoshi, H., \& Iwabuchi, H. (2011). Effect of sastrugi on snow 728 bidirectional reflectance and its application to MODIS data. Journal of Geophysical Research, $729 \quad 116,15$ PP. doi:201110.1029/2011JD016070

730 Li, W., Stamnes, K., Chen, B., \& Xiong, X. (2001). Snow grain size retrieved from near- infrared 731 radiances at multiple wavelengths. Geophysical Research Letters, 28(9), PAGES 1699-1702.

732 Luckman, A., Jansen, D., Kulessa, B., King, E. C., Sammonds, P., \& Benn, D. I. (2012). Basal crevasses 733 in Larsen C Ice Shelf and implications for their global abundance. The Cryosphere, 6(1), 113734 123. doi:10.5194/tc-6-113-2012

735 Machguth, H., Paul, F., Kotlarski, S., \& Hoelzle, M. (2009). Calculating distributed glacier mass balance 736 for the Swiss Alps from regional climate model output: A methodical description and 737 interpretation of the results. Journal of Geophysical Research, 114(D19), D19106. 738 doi:10.1029/2009JD011775

739 Markham, B. L., \& Helder, D. L. (2012). Forty-year calibrated record of earth-reflected radiance from 740 Landsat: A review Keywords: Landsat, Radiometric Calibration, History. MSS, TM, ETM+. 741 Remote Sensing of Environment, 122, 30-40. doi:10.1016/j.rse.2011.06.026

742 Michishita, R., Jiang, Z., Gong, P., \& Xu, B. (2012). Bi-scale analysis of multitemporal land cover 743 fractions for wetland vegetation mapping. ISPRS Journal of Photogrammetry and Remote $744 \quad$ Sensing, 72, 1-15.

745 Monserud, R., \& Leemans, R. (1992). Comparing Global Vegetation Maps with the Kappa-Statistic.

746 Ecological Modelling, 62(4), 275-293. doi:10.1016/0304-3800(92)90003-W

747 NASA. (2002, August). ASTER User Handbook, Version 2. Retrieved from

748 http://asterweb.jpl.nasa.gov/content/03_data/04_Documents/aster_user_guide_v2.pdf

749 NASA. (2011). Landsat 7 Science Data Users Handbook. National Aeronautics and Space

750 Administration. Retrieved from http://landsathandbook.gsfc.nasa.gov/

751 Nolin, A. W., \& Dozier, J. (1993). Estimating snow grain size using AVIRIS data. Remote Sensing of

752 Environment, 44(2-3), 231-238. doi:10.1016/0034-4257(93)90018-S 
753 Nolin, A. W., \& Payne, M. C. (2007). Classification of glacier zones in western Greenland using albedo and surface roughness from the Multi-angle Imaging SpectroRadiometer (MISR). Remote Sensing of Environment, 107(1-2), 264-275. doi:10.1016/j.rse.2006.11.004

Oerlemans, J. (1994). Quantifying Global Warming from the Retreat of Glaciers. Science, 264(5156), 243-245. doi:10.1126/science.264.5156.243

Orheim, O., \& Lucchitta, B. (1987). Snow and ice studies by thematic mapper and multispectral scanner landsat images. Annals of Glaciology, 9, 109-118.

Painter, T. H. (2011). Comment on Singh an others, "Hyperspectral analysis of snow reflectance to understand the effects of contamination and grain size". Journal of Glaciology, 57(201), 183185.

Paul, F. (2000). Evaluation of different methods for glacier mapping using Landsat TM. In EARSeL-SIGWorkshop Land Ice and Snow (Vol. 1, pp. 238-245). Desden/FRG.

Paul, F., Barrand, N. E., Berthier, E., Bolch, T., Casey, K. A., Frey, H., ... Winsvold, S. (2013). On the accuracy of glacier outlines derived from remote sensing data. Annals of Glaciology, 54(63), $171-182$.

Paul, F., Huggel, C., Kääb, A., Kellenberger, T., \& Maisch, M. (2002). Comparison of TM-Derived Glacier Areas with Higher Resolution Data Sets. EARSeL eProceedings, 2, 15-21. satellite data in Arctic Canada: Cumberland Peninsula, Baffin Island. Annals of Glaciology, 42,

773 Pellikka, P., \& Rees, W. G. (2010). Remote Sensing of Glaciers. London: CRC Press.

774 Phinn, S. R., Roelfsema, C. M., \& Mumby, P. J. (2012). Multi-scale, object-based image analysis for mapping geomorphic and ecological zones on coral reefs. International Journal of Remote Sensing, 33(12), 3768-3797. doi:10.1080/01431161.2011.633122 59-66. doi:10.3189/172756405781813087

\author{
Sensing, 33(12), 3768-3797. doi:10.1080/01431161.2011.633122
}

Pope, A., \& Rees, W. G. (In Press). Using in situ Spectra to Explore Landsat Classification of Glacier Surfaces. Journal of Applied Earth Observation and Geoinformation. 
779

780

781

782

783

784

785

786

787

788

789

790

791

792

793

794

795

796

797

798

799

800

801

802

803

804

Pope, A., Willis, I. C., Rees, W. G., Arnold, N. S., \& Pálsson, F. (2013). Combining airborne lidar and Landsat ETM+ data with photoclinometry to produce a digital elevation model for Langjökull, Iceland. International Journal of Remote Sensing, 34(4), 1005-1025. doi:10.1080/01431161.2012.705446

Rabatel, A., Dedieu, J.-P., Thibert, E., Letréguilly, A., \& Vincent, C. (2008). 25 years (1981-2005) of equilibrium-line altitude and mass-balance reconstruction on Glacier Blanc, French Alps, using remote-sensing methods and meteorological data. Journal of Glaciology, 54, 307-314. doi:10.3189/002214308784886063

Rabatel, A., Dedieu, J.-P., \& Vincent, C. (2005). Using remote-sensing data to determine equilibrium-line altitude and mass-balance time series: validation on three French glaciers, 19942002. Journal of Glaciology, 51, 539-546. doi:10.3189/172756505781829106

Rees, W. G. (2006). Remote Sensing of Snow and Ice. Boca Raton: Taylor \& Francis.

Rees, W. G. (2008). Comparing the spatial content of thematic maps. International Journal of Remote Sensing, 29(13), 3833-3844.

Rees, W. G., \& Arnold, N. S. (2007). Mass Balance and Dynamics of a Valley Glacier Measured by High-Resolution LiDAR. Polar Record, 43(04), 311-319. doi:10.1017/S0032247407006419

Reijmer, C. H., Knap, W. H., \& Oerlemans, J. (1999). The Surface Albedo of Vatnajokull Ice Cap, Iceland: A Comparison Between Satellite-Derived and Ground-Based Measurements. BoundaryLayer Meteorology, 92, 125-144.

Scambos, T. A., Frezzotti, M., Haran, T., Bohlander, J., Lenaerts, J. T. M., Van den Broeke, M., ... Winther, J.-G. (2012). Extent of low-accumulation "wind glaze" areas on the East Antarctic plateau: implications for continental ice mass balance. Journal of Glaciology, 58(210), 633-647. doi:10.3189/2012JoG11J232

Schaepman-Strub, G., Schaepman, M. E., Painter, T. H., Dangel, S., \& Martonchik, J. V. (2006). Reflectance quantities in optical remote sensing - definitions and case studies. Remote Sensing of Environment, 103(1), 27-42. doi:10.1016/j.rse.2006.03.002 
805 Shea, J. M., Menounos, B., Moore, R. D., \& Tennant, C. (2013). An approach to derive regional snow 806 lines and glacier mass change from MODIS imagery, western North America. The Cryosphere, 807 7(2), 667-680. doi:10.5194/tc-7-667-2013

808 Shukla, A., Gupta, R. P., \& Arora, M. (2009). Estimation of debris cover and its temporal variation using 809 optical satellite sensor data: a case study in Chenab basin, Himalaya. Journal of Glaciology, $810 \quad 55(191), 444-452$.

811 Sidjak, R. W., \& Wheate, R. D. (1999). Glacier mapping of the Illecillewaet icefield, British Columbia, 812 Canada, using Landsat TM and digital elevation data. International Journal of Remote Sensing, $813 \quad 20(2), 273-284$.

814 Sobrino, J. A., Oltra-Carrió, R., Sòria, G., Bianchi, R., \& Paganini, M. (2012). Impact of spatial 815 resolution and satellite overpass time on evaluation of the surface urban heat island effects. 816 Remote Sensing of Environment, 117, 50-56. doi:10.1016/j.rse.2011.04.042

817 Takeuchi, N. (2009). Temporal and spatial variations in spectral reflectance and characteristics of surface 818 dust on Gulkana Glacier, Alaska Range. Journal of Glaciology, 55(192), 701-709.

819 Van Angelen, J. H., Lenaerts, J. T. M., Lhermitte, S., Fettweis, X., Kuipers Munneke, P., Van den 820 Broeke, M. R., ... Smeets, C. J. P. P. (2012). Sensitivity of Greenland Ice Sheet surface mass 821 balance to surface albedo parameterization: a study with a regional climate model. The Cryosphere, 6(5), 1175-1186. doi:10.5194/tc-6-1175-2012

823 Williams, R. S., Hall, D. K., \& Benson, C. S. (1991). Analysis of glacier facies using satellite techniques. $824 \quad$ Journal of Glaciology, 37(125), 120-128.

825 Wiscombe, W. J., \& Warren, S. G. (1980). A Model for the Spectral Albedo of Snow. I: Pure Snow. 826 Journal of the Atmospheric Sciences, 37(12), 2712-2733.

827 Wolken, G. J., Sharp, M. J., \& Wang, L. (2009). Snow and ice facies variability and ice layer formation 828 on Canadian Arctic ice caps, 1999-2005. Journal of Geophysical Research, 114, F03011.

829 doi:10.1029/2008JF001173 

characteristics for snow, ice and water in the north of China. Hydrological Applications of Remote Sensing and Remote Data Transmissions, 145, 451-462.

\section{Figures:}

836 Figure 1: Comparison of spectral bands of the multispectral sensors considered in this study. Background 837 spectrum is the same as 'Fine Snow' in Figure 2.3. See Table S2 for further details.

838 Figure 2: False-colour ATM image of Midtre Lovénbreen collected on 9 August, 2003. ATM bands 4, 3,

839 and 2 are used for red, green, and blue respectively. Full colour versions for this and other figures are 840 available online.

841 Figure 3: Biplots of the first and second linear combinations of in situ spectral data from Midtre

842 Lovénbreen modified to mimic the spectral and radiometric properties of a range of multispectral

843 imagers. See Table 1 for the details of all individual plots, (a) through (p). The ellipses in Figure 3a also

844 show the three groups into which the data were classified.

845 Figure 4: Biplots of the first and second linear combinations of in situ spectral data from Langjökull 846 modified to mimic the spectral and radiometric properties of a range of multispectral imagers. See Table 2 847 for the details of all individual plots, (a) through (p). The ellipse in Figure 4a highlights the clean ice 848 spectra which were classified as distinct from the rest.

849 Figure 5: Midtre Lovénbreen surface classification using ATM imagery at $2 \mathrm{~m}$ resolution (a) and the 850 same image degraded to $20 \mathrm{~m}$ (b), $30 \mathrm{~m}$ (c), $60 \mathrm{~m}$ (d), and $250 \mathrm{~m}$ pixels (e). 


\section{Tables:}

854 Table 1: For Midtre Lovénbreen spectra: sensors, radiometric resolution, gain settings, $K$ (Cohen’s

855 Kappa) of clustering success, description of classification success (Monserud \& Leemans, 1992), and

856 corresponding panel in Figure 3.

\begin{tabular}{|l|c|c|c|c|c|}
\hline Sensor & $\begin{array}{c}\text { Radiometric } \\
\text { Resolution }\end{array}$ & $\begin{array}{c}\text { Gain } \\
\text { Settings }\end{array}$ & K & $\begin{array}{c}\text { Monserud } \\
\text { Agreement }\end{array}$ & Figure 6.1 \\
\hline ASTER & $8 \mathrm{bit}$ & $\mathrm{hi}$ & 0.9816 & Excellent & $\mathrm{b}$ \\
ASD FieldSpec & $8 \mathrm{bit}$ & - & 0.9742 & Excellent & $\mathrm{c}$ \\
ASD FieldSpec & $16 \mathrm{bit}$ & - & 0.9742 & Excellent & $\mathrm{d}$ \\
ASD FieldSpec & $12 \mathrm{bit}$ & - & 0.9742 & Excellent & $\mathrm{e}$ \\
Landsat MSS & $8 \mathrm{bit}$ & - & 0.9705 & Excellent & $\mathrm{f}$ \\
ASTER & $8 \mathrm{bit}$ & low 1 & 0.9669 & Excellent & $\mathrm{g}$ \\
ASD FieldSpec & - & - & 0.9669 & Excellent & $\mathrm{a}$ \\
ATM & $16 \mathrm{bit}$ & - & 0.9631 & Excellent & $\mathrm{h}$ \\
ASTER & $8 \mathrm{bit}$ & normal & 0.9595 & Excellent & $\mathrm{i}$ \\
Sentinel-2 & $12 \mathrm{bit}$ & - & 0.9484 & Excellent & $\mathrm{j}$ \\
Landsat TM / ETM+ & $8 \mathrm{bit}$ & LLLH & 0.9448 & Excellent & $\mathrm{k}$ \\
Landsat TM / ETM+ & $8 \mathrm{bit}$ & HHHH & 0.9267 & Excellent & 1 \\
MODIS 1-7 & $12 \mathrm{bit}$ & - & 0.9158 & Excellent & $\mathrm{m}$ \\
MODIS 8+ & $12 \mathrm{bit}$ & $\mathrm{hi}$ & 0.8938 & Excellent & $\mathrm{n}$ \\
MODIS 8+ & $12 \mathrm{bit}$ & lo & 0.8721 & Excellent & $\mathrm{o}$ \\
Landsat TM / ETM+ & $8 \mathrm{bit}$ & LLLL & 0.7977 & Very Good & $\mathrm{p}$ \\
\hline
\end{tabular}


860 Table 2: For Langjökull spectra: sensors, radiometric resolution, gain settings, K (Cohen’s Kappa) of

861 clustering success, description of classification success (Monserud \& Leemans, 1992), and corresponding

862 panel in Figure 4.

\begin{tabular}{|l|c|c|c|c|c|}
\hline Sensor & $\begin{array}{c}\text { Radiometric } \\
\text { Resolution }\end{array}$ & $\begin{array}{c}\text { Gain } \\
\text { Settings }\end{array}$ & $\boldsymbol{K}$ & $\begin{array}{c}\text { Monserud } \\
\text { Agreement }\end{array}$ & Figure 6.2 \\
\hline ASD FieldSpec & - & - & 1 & Perfect & $\mathrm{a}$ \\
ASD FieldSpec & $16 \mathrm{bit}$ & - & 1 & Perfect & $\mathrm{b}$ \\
ASD FieldSpec & $12 \mathrm{bit}$ & - & 1 & Perfect & $\mathrm{c}$ \\
ASD FieldSpec & $8 \mathrm{bit}$ & - & 1 & Perfect & $\mathrm{d}$ \\
Sentinel-2 & $12 \mathrm{bit}$ & - & 1 & Perfect & $\mathrm{e}$ \\
Landsat TM / ETM+ & $8 \mathrm{bit}$ & LLLH & 1 & Perfect & $\mathrm{f}$ \\
ASTER & $8 \mathrm{bit}$ & low 1 & 1 & Perfect & $\mathrm{g}$ \\
Landsat MSS & $8 \mathrm{bit}$ & - & 1 & Perfect & $\mathrm{h}$ \\
ASTER & $8 \mathrm{bit}$ & normal & 0.9081 & Excellent & $\mathrm{i}$ \\
MODIS 1-7 & $12 \mathrm{bit}$ & - & 0.6579 & Good & $\mathrm{j}$ \\
Landsat TM / ETM+ & $8 \mathrm{bit}$ & HHHH & 0.6559 & Good & $\mathrm{k}$ \\
ATM & $16 \mathrm{bit}$ & - & 0.5979 & Good & 1 \\
Landsat TM / ETM+ & $8 \mathrm{bit}$ & LLLL & 0.5841 & Good & $\mathrm{m}$ \\
ASTER & $8 \mathrm{bit}$ & $\mathrm{hi}$ & 0.5101 & Fair & $\mathrm{n}$ \\
MODIS 8+ & $12 \mathrm{bit}$ & $\mathrm{hi}$ & 0.4879 & Fair & $\mathrm{o}$ \\
MODIS 8+ & $12 \mathrm{bit}$ & $\mathrm{lo}$ & 0.3522 & Poor & $\mathrm{p}$ \\
\hline
\end{tabular}

863

864 
866 Table 3: Comparison of the results of the classifications presented in Figure 5 by considering relative

867 area of each class as well as their aggregation into glaciologically meaningful groups of accumulation and 868 ablation area.

\begin{tabular}{|c|c|c|c|c|c|}
\hline Class & $\begin{array}{c}2 \mathrm{~m} \\
\text { Pixels }\end{array}$ & Percent & Interpretation & & \\
\hline 1 & 124,425 & 9.7 & Shadow / Debris & \multirow{10}{*}{$\begin{array}{c}\text { Total Area: } \\
\text { Shadow/Debris: } \\
\text { Ablation: } \\
\text { Accumulation: }\end{array}$} & \multirow{10}{*}{$\begin{array}{l}25.0 \% \\
60.4 \% \\
14.7 \%\end{array}$} \\
\hline 2 & 196,744 & 15.3 & Shadow / Debris & & \\
\hline 3 & 57,694 & 4.5 & Ablation & & \\
\hline 4 & 67,947 & 5.3 & Ablation & & \\
\hline 5 & 107,323 & 8.3 & Ablation & & \\
\hline 6 & 158,711 & 12.3 & Ablation & & \\
\hline 7 & 205,371 & 16.0 & Ablation & & \\
\hline 8 & 179,783 & 13.0 & Ablation & & \\
\hline 9 & 116,938 & 9.1 & Accumulation & & \\
\hline 10 & 72,040 & 5.6 & Accumulation & & \\
\hline Class & $\begin{array}{c}20 \mathrm{~m} \\
\text { Pixels }\end{array}$ & Percent & Interpretation & & \\
\hline 1 & 1,383 & 10.5 & Shadow / Debris & \multirow{10}{*}{$\begin{array}{c}\text { Total Area: } \\
\text { Shadow/Debris: } \\
\text { Ablation: } \\
\text { Accumulation: }\end{array}$} & \multirow{10}{*}{$\begin{array}{l}25.0 \% \\
60.5 \% \\
14.2 \%\end{array}$} \\
\hline 2 & 1,932 & 14.7 & Shadow / Debris & & \\
\hline 3 & 610 & 4.6 & Ablation & & \\
\hline 4 & 653 & 5.0 & Ablation & & \\
\hline 5 & 1,023 & 7.8 & Ablation & & \\
\hline 6 & 1,479 & 11.3 & Ablation & & \\
\hline 7 & 2,307 & 17.6 & Ablation & & \\
\hline 8 & 1,883 & 14.3 & Ablation & & \\
\hline 9 & 1,107 & 8.4 & Accumulation & & \\
\hline 10 & 765 & 5.8 & Accumulation & & \\
\hline Class & $\begin{array}{c}30 \mathrm{~m} \\
\text { Pixels }\end{array}$ & Percent & Interpretation & & \\
\hline 1 & 630 & 10.6 & Shadow / Debris & \multirow{10}{*}{$\begin{array}{l}\text { Shadow/Debris: } \\
\text { Ablation: } \\
\text { Accumulation: }\end{array}$} & \multirow{10}{*}{$\begin{array}{l}25.7 \% \\
60.0 \% \\
14.3 \%\end{array}$} \\
\hline 2 & 889 & 15.0 & Shadow / Debris & & \\
\hline 3 & 287 & 4.8 & Ablation & & \\
\hline 4 & 288 & 4.9 & Ablation & & \\
\hline 5 & 454 & 7.7 & Ablation & & \\
\hline 6 & 624 & 10.5 & Ablation & & \\
\hline 7 & 1,005 & 17.0 & Ablation & & \\
\hline 8 & 895 & 15.1 & Ablation & & \\
\hline 9 & 491 & 8.3 & Accumulation & & \\
\hline 10 & 358 & 6.0 & Accumulation & & \\
\hline
\end{tabular}




\begin{tabular}{|c|c|c|c|c|c|}
\hline Class & $\begin{array}{c}60 \mathrm{~m} \\
\text { Pixels }\end{array}$ & Percent & Interpretation & & \\
\hline 1 & 167 & 10.8 & Shadow / Debris & \multirow{10}{*}{$\begin{array}{c}\text { Total Area: } \\
\text { Shadow/Debris: } \\
\text { Ablation: } \\
\text { Accumulation: }\end{array}$} & \multirow{10}{*}{$\begin{array}{l}25.6 \% \\
60.2 \% \\
14.2 \%\end{array}$} \\
\hline 2 & 228 & 14.8 & Shadow / Debris & & \\
\hline 3 & 93 & 6.0 & Ablation & & \\
\hline 4 & 87 & 5.6 & Ablation & & \\
\hline 5 & 92 & 6.0 & Ablation & & \\
\hline 6 & 153 & 9.9 & Ablation & & \\
\hline 7 & 240 & 15.6 & Ablation & & \\
\hline 8 & 264 & 17.1 & Ablation & & \\
\hline 9 & 119 & 7.7 & Accumulation & & \\
\hline 10 & 100 & 6.5 & Accumulation & & \\
\hline Class & $\begin{array}{l}250 \mathrm{~m} \\
\text { Pixels }\end{array}$ & Percent & Interpretation & & \\
\hline 1 & 15 & 13.4 & Shadow / Debris & \multirow{10}{*}{$\begin{array}{l}\text { Shadow/Debris: } \\
\text { Ablation: } \\
\text { Accumulation: }\end{array}$} & \multirow{10}{*}{$\begin{array}{l}27.7 \% \\
54.5 \% \\
17.9 \%\end{array}$} \\
\hline 2 & 16 & 14.3 & Shadow / Debris & & \\
\hline 3 & 7 & 6.3 & Ablation & & \\
\hline 4 & 11 & 9.8 & Ablation & & \\
\hline 5 & 7 & 6.3 & Ablation & & \\
\hline 6 & 6 & 5.4 & Ablation & & \\
\hline 7 & 13 & 11.6 & Ablation & & \\
\hline 8 & 17 & 15.2 & Ablation & & \\
\hline 9 & 11 & 9.8 & Accumulation & & \\
\hline 10 & 9 & 8.0 & Accumulation & & \\
\hline
\end{tabular}


872 Table 4: Comparison of the results of the classifications presented in Figure 5 by down-sampling results

873 with majority filtering to lower resolutions. A is overall agreement and $\mathrm{K}$ is Cohen's Kappa, both

874 presented in Section 4.5; perfect agreement would lead to a value of 1 for both A and K.

\begin{tabular}{|c|c|c|c|c|c|c|c|}
\hline $\begin{array}{c}\text { Starting } \\
\text { Resolution }\end{array}$ & $\begin{array}{c}\text { Final } \\
\text { Resolution }\end{array}$ & $\boldsymbol{A}$ & $\begin{array}{c}\boldsymbol{A}, \\
\text { grouped }\end{array}$ & $\begin{array}{c}\boldsymbol{A}, \\
\text { ranked }\end{array}$ & $\boldsymbol{K}$ & $\begin{array}{c}\boldsymbol{K}, \\
\text { grouped }\end{array}$ & $\begin{array}{c}\boldsymbol{K}, \\
\text { ranked }\end{array}$ \\
\hline $2 \mathrm{~m}$ & $30 \mathrm{~m}$ & 0.6315 & 0.9477 & 1 & 0.5825 & 0.9035 & 1 \\
$2 \mathrm{~m}$ & $20 \mathrm{~m}$ & 0.7217 & 0.9459 & 2 & 0.6837 & 0.9017 & 2 \\
$20 \mathrm{~m}$ & $30 \mathrm{~m}$ & 0.5788 & 0.9324 & 3 & 0.5226 & 0.8746 & 3 \\
$30 \mathrm{~m}$ & $60 \mathrm{~m}$ & 0.6414 & 0.9084 & 6 & 0.5927 & 0.8360 & 4 \\
$2 \mathrm{~m}$ & $60 \mathrm{~m}$ & 0.5284 & 0.9135 & 4 & 0.4662 & 0.8359 & 5 \\
$20 \mathrm{~m}$ & $60 \mathrm{~m}$ & 0.6126 & 0.9090 & 5 & 0.5605 & 0.8326 & 6 \\
$60 \mathrm{~m}$ & $250 \mathrm{~m}$ & 0.2857 & 0.7727 & 7 & 0.1881 & 0.5956 & 7 \\
$30 \mathrm{~m}$ & $250 \mathrm{~m}$ & 0.1923 & 0.7612 & 8 & 0.0878 & 0.5681 & 8 \\
$20 \mathrm{~m}$ & $250 \mathrm{~m}$ & 0.1975 & 0.6857 & 10 & 0.1023 & 0.4554 & 9 \\
$2 \mathrm{~m}$ & $250 \mathrm{~m}$ & 0.2405 & 0.6912 & 9 & 0.1425 & 0.4322 & 10 \\
\hline
\end{tabular}

875

876 
878 Table 5: Comparison of the results of the classifications presented in Figure 5 by downscaling results to

879 higher resolutions. A is overall accuracy agreement and K is Cohen's Kappa, both described in Section

8804.5 ; perfect agreement would lead to a value of 1 for both A and K.

\begin{tabular}{|c|c|c|c|c|c|c|c|}
\hline $\begin{array}{c}\text { Starting } \\
\text { Resolution }\end{array}$ & $\begin{array}{c}\text { Final } \\
\text { Resolution }\end{array}$ & $\boldsymbol{A}$ & $\begin{array}{c}\boldsymbol{A}, \\
\text { grouped }\end{array}$ & $\begin{array}{c}\boldsymbol{A}, \\
\text { ranked }\end{array}$ & $\boldsymbol{K}$ & $\begin{array}{c}\boldsymbol{K}, \\
\text { grouped }\end{array}$ & $\begin{array}{c}\boldsymbol{K}, \\
\text { ranked }\end{array}$ \\
\hline $30 \mathrm{~m}$ & $20 \mathrm{~m}$ & 0.7381 & 0.9603 & 1 & 0.7030 & 0.9269 & 1 \\
$20 \mathrm{~m}$ & $2 \mathrm{~m}$ & 0.6393 & 0.9585 & 2 & 0.5918 & 0.9233 & 2 \\
$30 \mathrm{~m}$ & $3 \mathrm{~m}$ & 0.5976 & 0.9450 & 3 & 0.5443 & 0.8983 & 3 \\
$60 \mathrm{~m}$ & $30 \mathrm{~m}$ & 0.6383 & 0.9338 & 4 & 0.5902 & 0.8778 & 4 \\
$60 \mathrm{~m}$ & $20 \mathrm{~m}$ & 0.5958 & 0.9252 & 5 & 0.5422 & 0.8609 & 5 \\
$60 \mathrm{~m}$ & $2 \mathrm{~m}$ & 0.4977 & 0.9065 & 6 & 0.4317 & 0.8253 & 6 \\
$250 \mathrm{~m}$ & $60 \mathrm{~m}$ & 0.2612 & 0.6909 & 7 & 0.1690 & 0.4469 & 7 \\
$250 \mathrm{~m}$ & $30 \mathrm{~m}$ & 0.2342 & 0.6833 & 8 & 0.1400 & 0.4223 & 8 \\
$250 \mathrm{~m}$ & $20 \mathrm{~m}$ & 0.2165 & 0.6711 & 9 & 0.1207 & 0.3985 & 9 \\
$250 \mathrm{~m}$ & $2 \mathrm{~m}$ & 0.2145 & 0.6647 & 10 & 0.1190 & 0.3883 & 10 \\
\hline
\end{tabular}

881 